\title{
How fast should we innovate?
}

\section{Thomas Vogt}

To cite this article: Thomas Vogt (2016) How fast should we innovate?, Journal of Responsible Innovation, 3:3, 255-259, DOI: 10.1080/23299460.2016.1258941

To link to this article: http://dx.doi.org/10.1080/23299460.2016.1258941

$$
\text { 册 Published online: } 21 \text { Nov } 2016 .
$$

Submit your article to this journal ๘

Lll Article views: 10

Q View related articles $\longleftarrow$

View Crossmark data ¿

Citing articles: 1 View citing articles ¿ 
DISCUSSION PAPER

\title{
How fast should we innovate?
}

\author{
Thomas Vogt 1
}

NanoCenter \& Department of Chemistry \& Biochemistry, University of South Carolina, Columbia, SC, USA

\begin{abstract}
The role of speed in innovations needs to be explored more thoroughly. I advocate here that for innovations which rely on scarce materials, research into more abundant substitutes needs to be accelerated while a regulatory-driven extension of the product life should slow down the number of incremental innovations and reduce our overall footprint on scarce resources. Chemical elements need to be established as global commons whose overuse can be regulated if required. Part of the efficiency gains of innovations could be used for research to offset the 'rebound effect' and provide the public with a return on early infrastructure investments.
\end{abstract}

\section{ARTICLE HISTORY}

Received 14 September 2015

Accepted 7 November 2016

\section{KEYWORDS}

Innovation; innovation and speed; commons; rebound effect; non-equilibrium economics

Recent claims that innovation is slowing down (Huebner 2005) and focused primarily on incremental improvements of technologies rather than the emergence of new transformational general purpose technologies such as electricity, internal combustion engines, or the integrated circuit (Gordon 2016) have been met with ridicule by Bill Gates (Friedman 2014) and scorned by seasoned utopians such as Ray Kurzweil (Kurzweil 2005) who sees us on a path towards 'the singularity', where computational capabilities will match the pattern-recognition powers, problem-solving skills, and emotional and moral intelligence of humans.

While the question of how long exponential or hyper-exponential growth of certain technological capabilities such as epitomized in Moore's law can be sustained (The Economist March 12, 2016), or of whether in certain fields we are currently witnessing an equilibrium phase that will be punctuated by discoveries and innovations in the near future are indeed important, it appears to me that we need to ask more a fundamental question, namely what speed should a particular innovation have? Are there reasons for us to accelerate or slow down an innovation? Is there an optimal speed for any given innovation? Is fast innovation always better? Do we need to depart from our timeless notion of innovation described within the framework of equilibrium economics and explore time as an important parameter within a non-equilibrium framework where, as W. Brian Arthur (Arthur 2015) points out, '... time, in the sense of real historical time, becomes important ...'? An equally important question is who, if anyone, should control the speed of innovation? Can and should local, national and international bodies of governance intervene by using financial and regulatory tools to deliberately 
accelerate or slow down the pace of certain innovations? Is there such a thing as an 'overheated innovation environment'?

In the following, I will focus only on innovations based predominantly on matter (atoms) and not algorithms (bits), and I posit that for material products speed will increasingly become an important parameter in the innovation cycle. I advocate a highly contested position, namely that public interventions need to target and slow down certain innovations relying heavily on limited resources and accelerate the search for more abundant substitutes to 'buy us enough time' to develop new sustainable economic and civil structures. Part of my underlying thinking that innovations are inefficient processes with unpredictable time lines and speeds was outlined in more detail in a previous paper (Vogt 2010).

Equilibrium macroeconomics allows us to understand how prices and goods produced and consumed are consistent with observed price pattern and quantities of goods. This economic model does not take into account time as an economic parameter. In contrast, in dynamical complexity economics time becomes an important parameter because one is not at equilibrium. Equilibrium describes a balanced system in which all rates of change cancel each other. Arthur (2015) uses traffic flow as a simple metaphor for nonequilibrium processes and points out that traffic jams cannot occur at equilibrium but emerge spontaneous and are best explored using statistical approaches. Emergence implies a certain level of unpredictability and time-uncertainty for the occurrence of an individual event. While many traffic models are statistically quite accurate, the question of where and when a traffic jam will occur is often not answerable. Furthermore, traffic jams do not occur at the individual car level (micro level) or at the macro level of overall traffic flow, but at an intermediate meso-level, such as a localized cluster of cars. Optimization strategies and policy arguments for or against the implementation of traffic speed limits focus on cost functions such as fuel efficiency and the reduction of accidents. External cost functions such as gas prices can fluctuate considerably and not be predictable. Innovations are also subject to external cost functions such as unpredictable funding streams and fluctuating resource prices possibly caused by political unrest. This can have significant impact on the market penetration of new products. Not considering the speed of innovations does not capture the essence of innovations being both path- and time-dependent.

In a recent study, Graedel et al. (2015) showed that in the case of resource constraints of 62 technologically important metals, not one of them can be substituted by another one for all major applications, and that for a dozen metals potential substitutes are inadequate or do not exist at all. The materials and chemical element footprint of complex technologies such as modern computer chips, which can contain more than 60 different chemical elements, often includes scarce metals which currently cannot be substituted by more abundant ones. Developments in existing and emerging economies with rapidly growing consumer populations will exacerbate resource demands for key chemical elements. In some cases this might lead to a temporary depletion of one or more key chemical elements which could result in a compromised product performance or even its availability. Resource management of chemical elements and materials has become an increasingly important part of cradle-to-grave product development. Important research efforts for more abundant elemental or material substitutes have very unpredictable time lines and require prolonged financial commitments to be successful. Besides sustaining such research efforts, a regulatory-driven lengthening of certain product 
lifetimes and the elimination of product lines not meeting a certain innovation threshold would reduce the materials footprint. In the current political context, both interventions would most likely be challenged as heavy-handed governmental interference. However, the impact of temporary resource constraints for chemical elements such as the Rare Earth metals has been debated intensely in the past years (Department of Energy 2011).

Rare Earth metals have been identified as critical resources for many technologies such as compact fluorescent and LED lighting, magnets, catalysts, catalytic converters, batteries and pigments. Programs to substitute more abundant chemical elements have been slow in getting off the ground and have difficulty in securing longer term funding. The lead time on such research is long and unpredictable and the expectations for success are initially often too high. Responsible innovation needs to identify potential resource constraints early on and accelerate research for more abundant substitutes. Lifecycles of products based on scarce materials and chemical elements should be extended. Users routinely abandon products such as hand-held devices and computers due to the availability of new products with often only marginal performance improvements. An artificially accelerated innovation cycle attempts to generate profits from hardware upgrades even though less expensive software upgrades could be supported by an existing hardware platform. Prolonging product lifetimes can be incentivized by providing tax deductions and higher trade-in values as well as by exploring more efficient re-cycling and re-purposing of traded-in products made from scarce resources.

This would help counterbalance the fact that, in some cases, more efficient use of material resources can lower costs while concomitantly increasing demand and thereby triggering economic growth, which itself further amplifies resource use. This is called the 'rebound effect' and has been discussed in many sectors (Greening, Greene, and Difiglio 2000; Freire-Gonzalez 2010; Jalas 2002). It has been suggested that removing certain efficiency gains from the economic cycle and replenishing natural (Constanza and Daly 1992) ('strong sustainability') and human made capital (Rees and Wackernagel 1995) ('weak sustainability') would be a more responsible approach to innovation. One could use part of the sequestered gains for the research and development of products with more abundant materials, increase the product lifetime and explore creative re-uses of recycled products. Policies to assess resource limits, develop and use more abundant materials in products and sequester part of the financial returns for $R \& D$ efforts to move towards an economy with weak sustainability is likely to be challenged. However, there are compelling arguments for this approach.

Chemical elements should be viewed as global commons which, like water, can be privately owned but their use still regulated. The fact that chemical elements, in contrast to genes and man-made radioisotopes, cannot be patented suggests that they represent a tacit commons and provides a leverage point for arguing against their excessive use. The arguments for international regulation to protect them as commons for future generations are similar to those made against excessive logging, overuse of water, over-fishing and the depletion of wetlands and forests.

On a larger scale it is often the 'visible hand' of the state rather than the free market that enables innovation due to substantial and early high-risk investments. Perez (2013) suggests that 'given the massive returns generated by their success, shouldn't entrepreneurs then return some of the rewards to the government, so it can continue taking the big risks that can later be turned into market game-changers?' Replenishing public 
funds used for the initial development of large scientific infrastructure projects such as in the National Nanotechnologies Initiative (www.nano.gov) with some of the returns of commercially successful innovations could be a way to provide a more sustained longterm support for science and engineering research.

Innovation is an unpredictable, non-equilibrium process which is strongly dependent on invention (basic and applied $\mathrm{R} \& \mathrm{D}$ ) and societal acceptance and is ultimately judged by the market penetration of the developed product. These three processes have very different time scales and each can determine the success of the final technology. Stranded technologies such as supersonic aviation and declining technology platforms such as nuclear energy production based on nuclear fission point to the importance of societal acceptance of technologies, whereas the up to now unfulfilled promises of nuclear fusion exemplifies cases where science and engineering has not yet provided a marketready device and thus large-scale projects such as ITER (www.iter.org) or NIF (https:// lasers.llnl.gov) cannot be managed within projected time lines. Time is a very complex parameter in innovation and it clearly needs more attention. Certain projects would benefit from much longer incubation periods with lower end-use expectations and more time spent for unaccounted basic research. Other innovations based on the use of more abundant materials need to be accelerated and not treated as an afterthought.

There is a long tradition describing technological changes and innovation using the model of punctuated equilibrium grafted from evolutionary biology (Levinthal 1998). Extended periods of little or no developments are interrupted by short bursts of change. I posit here that in the long run slower innovation can be a more efficient process as it allows the exploration of a wider parameter space and allows sustainable materials compositions to be developed. Brian Arthur describes technologies as being assembled from different components and hierarchically organized in many different layers of groupings and combinations - a property referred to as recursive (Arthur 2009). Invention, a prerequisite for innovation, is thus a process of recursive problem-solving and innovating too fast can lead to suboptimal solutions.

Our view of innovation has radically changed over the past 50 years. We now realize that every innovation has a Janus-faced kernel that is capable of both developing into a desirable and enabling technology and harming our environment, depleting some of our commons and having unforeseen impacts on our daily lives. Innovation and risk are the two faces of modernity. Technological and political complexities create uncertainties which often defy long-term planning - the future is no longer foreseeable (if it ever was); rather, it must be felt out every step of the way. Such a process requires sufficient time and ample resources.

\section{Acknowledgements}

This research received no specific grant from any funding agency in the public, commercial, or not for-profit sectors.

\section{Notes on contributor}

Thomas Vogt is the Educational Foundation Distinguished Professor of Chemistry and Biochemistry at the University of South Carolina. His research focuses on the structural characterization of 
new materials. His other interests are in the history and philosophy of science, epistemology, innovation and science policy. He is a Fellow of the American Physical Society and the American Association for the Advancement of Science.

\section{ORCID}

Thomas Vogt (D) http://orcid.org/0000-0002-4731-2787

\section{References}

Arthur, W. Brian. 2009. The Nature of Technology - What It Is and How It Evolves. New York: Free Press.

Arthur, W. Brian. 2015. "Complexity Economics: A Different Framework for Economics Though" to Appear in the Book "Complexity and the Economy" W.B. Arthur. Oxford: Oxford University Press.

Constanza, R., and H. E. Daly. 1992. "Natural Capital and Sustainable Development." Conservation Biology 6: 37-46.

Department of Energy. 2011. "US Critical Metals Strategy." Accessed 21 August 2014. http://energy. gov/sites/prod/files/DOE_CMS2011_FINAL_Full.pdf.

Freire-González, J. 2010. "Empirical Evidence of Direct Rebound Effect in Catalonia." Energy Policy 38 (5): 2309-2314.

Friedman, Uri. 2014. “The Idea that Innovation Is Slowing Down Is Stupid.” The Atlantic, 12 March 2014. Accessed 21 August 2014. http://www.theatlantic.com/international/archive/2014/03/billgates-the-idea-that-innovation-is-slowing-down-is-stupid/284392/.

Gordon, Robert J. 2016. The Rise and Fall of American Growth: The U.S. Standard of Living Since the Civil War. Princeton, NJ: Princeton University.

Graedel, T. E., E. M. Harper, N. T. Nassar, and Barbara K. Reck. 2015. “On the Materials Basis of Modern Society.” Proceedings of the National Academy of Sciences 112 (20): 6295-6300. doi:10. 1073/pnas.1312752110.

Greening, Lorna, David L. Greene, and Carmen Difiglio. 2000. "Energy Efficiency and Consumption - The Rebound Effect - A Survey." Energy Policy 28: 389-401.

Huebner, Jonathan. 2005. “A Possible Declining Trend for Worldwide Innovation.” Technological Forecasting and Social Change 72: 980-986.

Jalas, Mikko. 2002. “A Time Use Perspective on the Materials Intensity of Consumption.” Ecological Economics 41: 101-123.

Kurzweil, Ray. 2005. The Singularity Is Near: When Humans Transcend Biology. New York, NY: The Viking Press.

Levinthal, Daniel A. 1998. "The Slow Pace of Rapid Technological Change: Gradualism and Punctuation in Technological Change." Industrial and Corporate Change 7 (2): 217-247.

Perez, Carlota. 2013. "Debunking Public vs. Private Sector Myths.” In The Entrepreneurial State, edited by Mariana Mazzucato, xxiii-xxiv. New York: Anthem Press.

Rees, W. E., and M. Wackernagel. 1995. Our Ecological Footprint: Reducing Human Impact on Earth. Gabriola Island, BC: New Society Publishers.

“Technology Quarterly - After Moore's Law.” The Economist, 12 March 2016. Accessed 30 September 2016. http://www.economist.com/technology-quarterly/2016-03-12/after-mooreslaw.

Vogt, Thomas. 2010. "Buying Time - Using Nanotechnologies and Other Emerging Technologies for a Sustainable Future." In Understanding Nanotechnology, edited by U. Fiedeler, Christopher Coenen, Sarah R. Davies, and Arianna ferrari, 43-60. Heidelberg: AKA Verlag. 